\title{
An overview of Bertram Scharf's research in France on loudness adaptation
}

\author{
Sabine Meunier* \\ LMA, CNRS, UPR 7051, Aix-Marseille Univ, Centrale Marseille, F-13402 Marseille Cedex \\ 20, France \\ Marseille, 13402, France, France, meunier@Ima.cnrs-mrs.fr
}

Since 1978, Professor Bertram Scharf divided his time between the USA and France. He was a Visiting Scientist at the Laboratoire de Mécanique et d'Acoustique in Marseille until the mid-1990s and collaborated with the University of Marseille (Faculté de Médecine) until his death. One of Bertram Scharf's major contributions to the field of psychoacoustics is in the area of loudness. He first studied spectral loudness summation, when he started working at Harvard University. In France, his work on loudness focused mainly on loudness adaptation. He wrote, "Loudness resembles pain in that it decreases as a function of time only under special stimulus conditions." Bertram Scharf's work with his French colleagues defined aspects of loudness adaptation in its direct (simple loudness adaptation) and indirect (induced loudness adaptation) forms. They studied how the auditory system recovers from loudness adaptation and examined a possible physiological basis for loudness adaptation.

\section{INTRODUCTION}

Professor Bertram Scharf traveled a lot as a Visiting Scientist in Germany, Finland and France. France became his second home and, since 1978, he split his time between Boston and Marseille (or Cassis). In Marseille, he worked at the "Laboratoire de Mécanique et d'Acoustique" (Mechanics and Acoustics Laboratory) with Georges Canévet who has created the psychoacoustics team in the laboratory. Bertram Scharf was part of this "adventure". Afterward, he worked at the "Université d'Aix-Marseille, Faculté de Médecine" where he started his work on the role of the olivocochlear bundle in hearing.

A lot of Bertram Scharf's contributions in psychoacoustics concerned loudness: spectral loudness summation (among his first publications), binaural summation of loudness, loudness adaptation, induced loudness reduction. Bertram Scharf also orientated his work on frequency selectivity and the role of attention in frequency selectivity. He had several contributions on binaural hearing and auditory localization, especially when working in Marseille with Georges Canévet and Jens Blauert from Bochum (Germany). In Marseille, he collaborated with physicians on the role of the olivocochlear bundle in hearing. A pioneer study that could be developed because of the cooperation between Bertram Scharf and surgeons in Marseille that used vestibular neurotomies in the surgical management of incapacitating Meniere's disease, during which the olivocochlear bundle is severed.

In this paper, we will focus on Bertram Scharf's contributions to loudness adaptation.

A sensory system adapts when the sensation decreases over time while the physical stimulus is constant. A lot of sensations adapt: brightness, odor intensity, taste. For example, when exiting from a dark room, the brightness of the sun seems very strong while it decreases after a certain time of adaptation. For a long time, "the question of: does loudness adapt?" was asked. Bertram Scharf and his colleagues gave a first answer: "Loudness may adapt, after all" (Fishken et al., 1961). But "Loudness resembles pain in that it decreases as a function of time only under special stimulus conditions." (Scharf, 1983).

Different studies showed a decrease in the loudness of a steady stimulus over the first 2 or 3 minutes of exposure. However, in most of the experiments, an interaural matching procedure was used (Hood, 1950; Egan, 1955 for example). A continuous sound, with constant level and frequency, was presented to one ear; the task of the listener was to adjust the level of a brief sound, played intermittently to the other ear, in order to make it equal in loudness to the continuous sound. After some minutes of exposure to the continuous sound, the level of the intermittent sound was decreased, showing a decrease in the loudness of the continuous sound. However, when no contralateral signal was used, very little adaptation was found (Canévet et al., 1981; Scharf, 1983); when it appears, it is called simple loudness adaptation, in contrast to induced loudness adaptation when loudness adapation is induced by a second sound, such as in measurements using matching procedures. 


\section{SIMPLE LOUDNESS ADAPTATION}

In order to measure simple loudness adaptation, procedures are required that do not involve matching between two sounds. Scharf (1983) reviewed some of those procedures: absolute judgments, cross-modality matching and tracking. Among the absolute judgment procedures, Bertram Scharf proposed the method of successive magnitude estimation "whereby the observer assigns numbers to express the loudness of a sound at successive time intervals" (see figure 1).

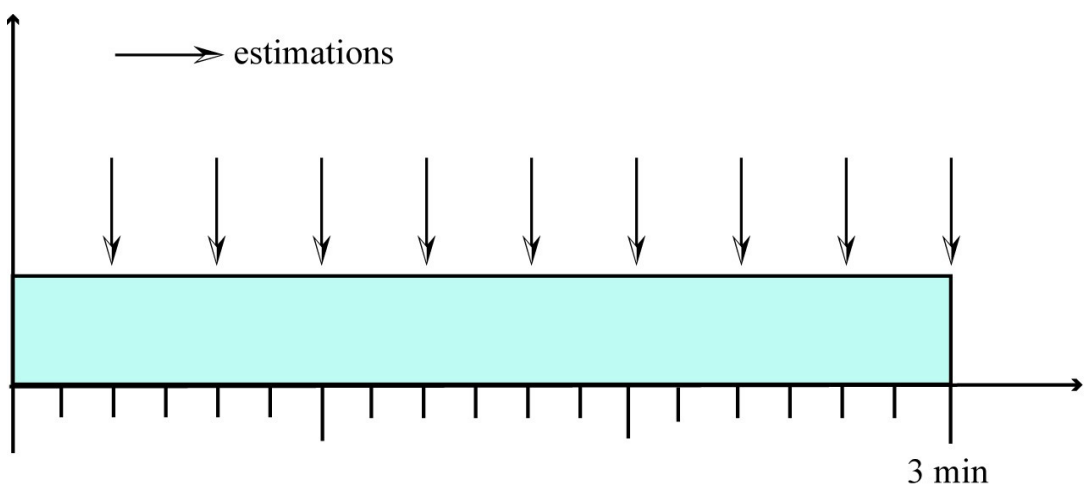

Time

FIGURE 1. The method of successive magnitude estimation.

Simple loudness adaptation occurs in very few cases. It has been observed only for pure tones, broadband noise adapts little (Scharf, 1983; Scharf and Canévet, 1989). Simple loudness adaptation is very strong, sometimes complete, at the lowest sensation levels $(<20 \mathrm{~dB} \mathrm{SL})$. Complete adaptation means that the sounds become inaudible. For levels above $20 \mathrm{~dB}$ SL, adaptation decreases rapidly, and disappears for levels above $40 \mathrm{~dB}$ SL (Canévet et al., 1981, Scharf, 1983, figure 2).

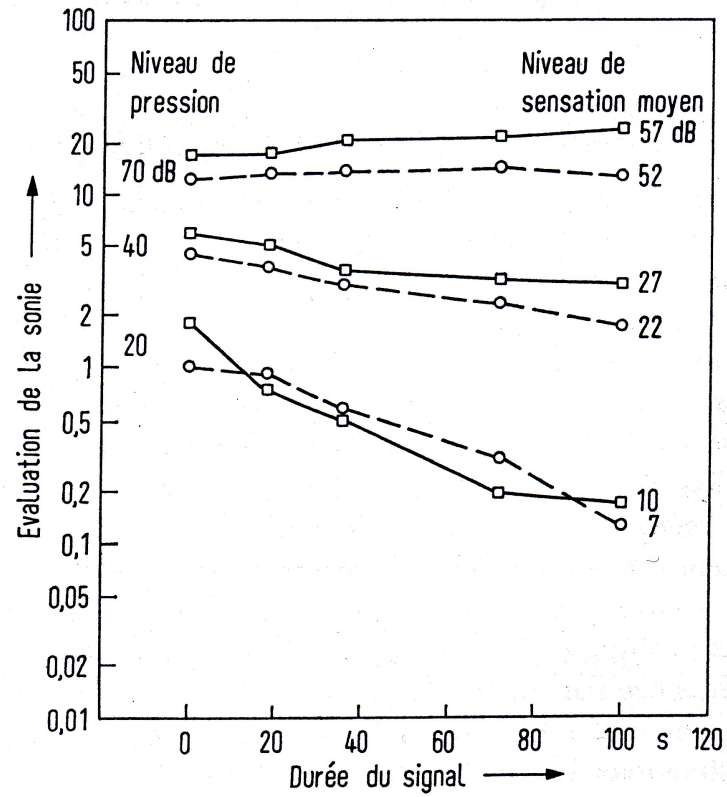

FIGURE 2. Loudness adaptation for a 4-kHz pure tone at different levels. (From Canévet et al., 1981). The loudness estimate (Evaluation de la sonie) is plotted as a function of the time after the signal onset (Durée du signal). The sound pressure level is indicated on the left (Niveau de pression) and the mean sensation level is indicated on the right (Niveau de sensation moyen)

The circles are for monaural conditions and the squares for binaural conditions 
Adaptation increases with frequency (Canévet et al., 1981; Scharf, 1983, see figure 3). High-frequency puretones produce more adaptation than low-frequency pure-tones: Bertram Scharf and his colleagues (Miskiewicz et al., 1993) showed that, at a high frequency, simple loudness adaptation can take place at relatively high sensation levels (40 dB SL, see figure 3). Bertram Scharf and his colleagues (Hellman et al., 1997; Miskiewicz et al., 1993) assumed that adaptation takes place when excitation is restricted to a narrow region of the cochlea. This hypothesis is supported by the strong adaptation observed for high frequencies as well as for low-level sounds that both provide a restricted spread of excitation.

Modulated sounds produce less adaptation than continuous sounds (Scharf, 1983) and there are large interindividual differences in the magnitude of adaptation. Most listeners show a decrease in loudness of about $50 \%$ after one minute of exposure to a high-frequency pure tone at a low level; but some listeners may report no change in the loudness, whereas for other listeners the sound becomes inaudible (Scharf, 1983). Scharf (1983) did not find intraindividual differences in the magnitude of adaptation among different sessions. It seems then, that the capacity of loudness to adapt is an individual characteristic.
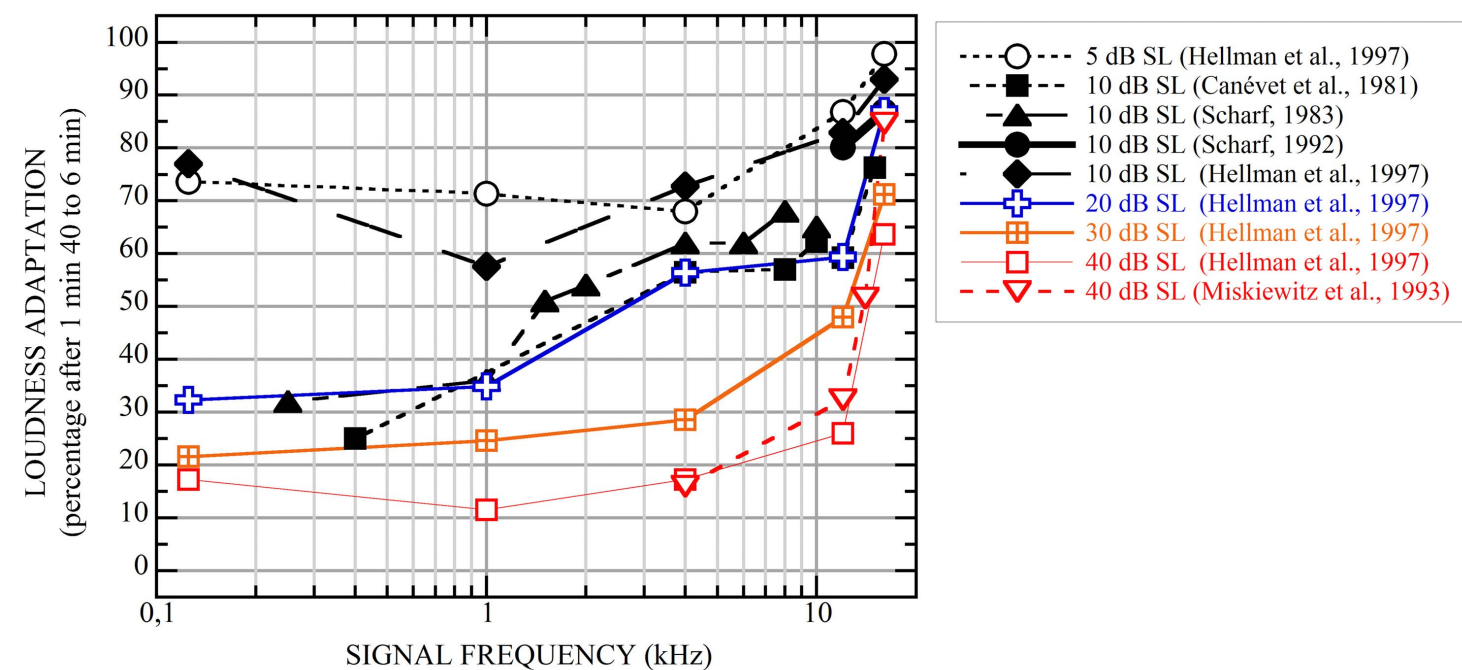

FIGURE 3. Loudness adaptation as a function of frequency for different sensation levels. Loudness adaptation is defined as the percentage of decline: $100($ Ei-Ef)/Eg

Where $\mathrm{Ei}=$ the initial loudness estimate,

$\mathrm{Ef}=$ the loudness estimate at the end of the experiment (after 1 min 40 to 6 min depending on the study),

$\mathrm{Eg}=$ the greater of the two

\section{CONTRALATERALLY INDUCED LOUDNESS ADAPTATION}

As described previously, the loudness of a steady sound at high levels also decreases over time when played simultaneously with an intermittent sound in the contralateral ear (contralaterally induced loudness adaptation, figure 4). Many papers co-authored by Bertram Scharf and his french colleagues have reported this effect (for example Scharf, 1983; Botte et al., 1982; Canévet et al. 1983, 1985, 1989).

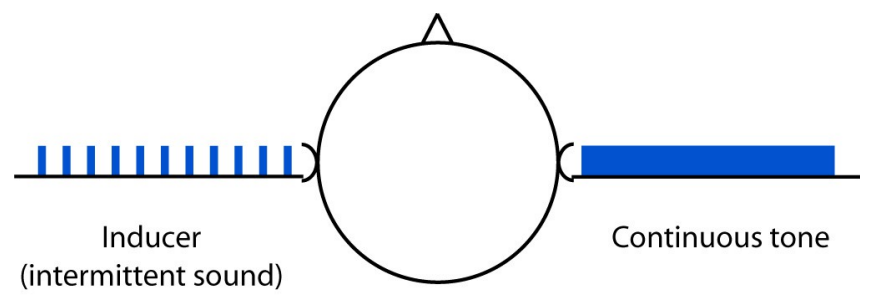

FIGURE 4. Contralaterally induced loudness adaptation 
Figure 5 shows an example of contralaterally induced loudness adaptation (dichotic condition) for a $1000-\mathrm{Hz}$ pure tone at $60 \mathrm{~dB}$ SPL (from Botte et al., 1982).

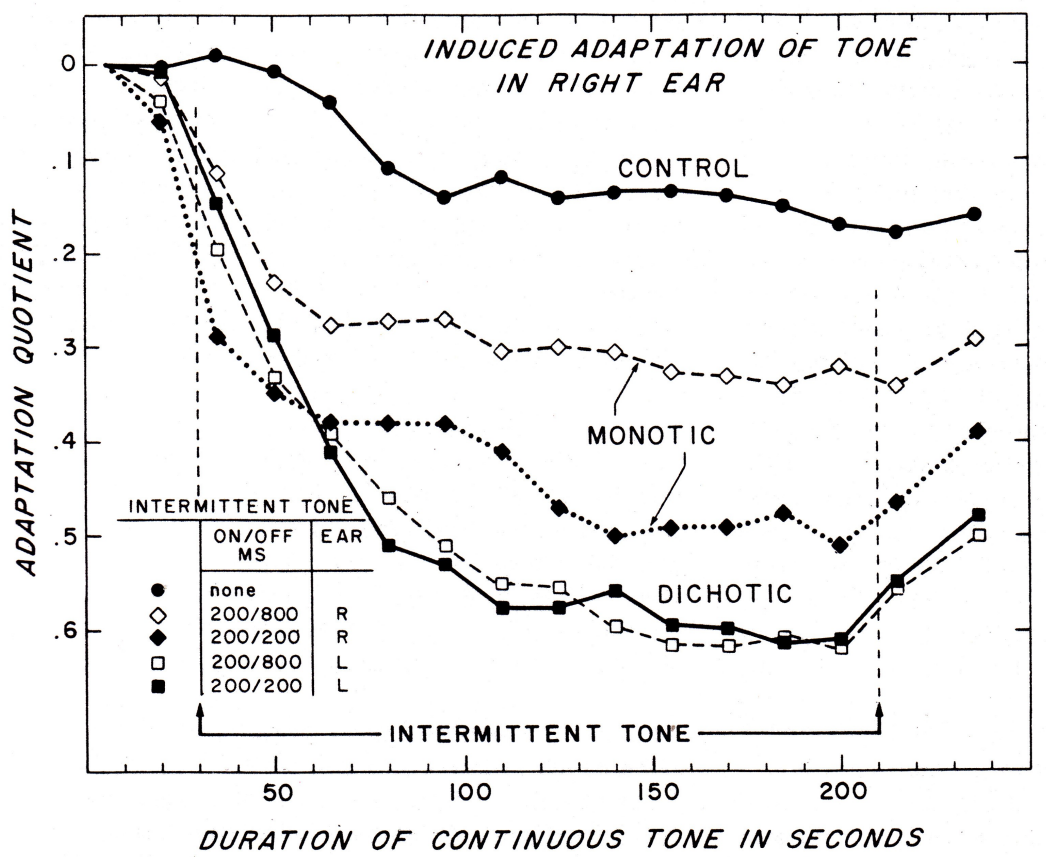

Figures 5. Loudness adaptation for a continuous $1000-\mathrm{Hz}, 60-\mathrm{dB}$ tone in the right ear.

The adaptation quotient is plotted as a function of the continuous tone duration. The adaptation quotient is defined as: (Ei-Ef)/Eg (see figure 3).

In the control condition the continuous tone was presented alone.

The dichotic condition corresponds to contralaterally induced loudness adaptation where an intermittent tone is played to the left ear at the same time as the continuous tone in the other ear.

The monotic condition correponds to ipsilaterally induced loudness adaptation where the intermittent tone is played to the right ear with the continuous tone.

The continuous tone was on for 4 min. The intermittent tone started $30 \mathrm{~s}$ after the beginning of the continuous tone and lasted 180 s. (From Botte et al., 1982).

Contralaterally induced loudness adaptation was observed at relatively high levels (40 and $60 \mathrm{~dB}$ SL) of the continuous sounds (Botte et al., 1982, 1986; Canévet et al., 1985). It increases with frequency but not as much as simple adaptation (Botte et al., 1982, 1986). It is observed even when the inducer and the continuous tones frequencies differ (Botte et al., 1982, 1986). But, contralaterally induced loudness adaptation is selective in frequency; a stronger effect was found for inducer frequencies close to the continuous tone frequencies (Botte et al., 1982, 1986). An inducer at the same level or lower than the continuous tone, may induce loudness adaptation (Botte et al., 1982; Canévet et al., 1985).

\section{IPSILATERALLY INDUCED LOUDNESS ADAPTATION}

Loudness adaptation may also be induced by an intermittent sound presented to the same ear (ipsilaterally induced loudness adaptation, figure 6). Bertram Scharf's contribution to ipsilaterally induced loudness adaptation can be found for example in Scharf (1983), Canévet et al. (1983, 1985, 1989), Scharf et al. (1986). In figure 5, the monotic condition corresponds to ipsilaterally induced loudness adaptation. 


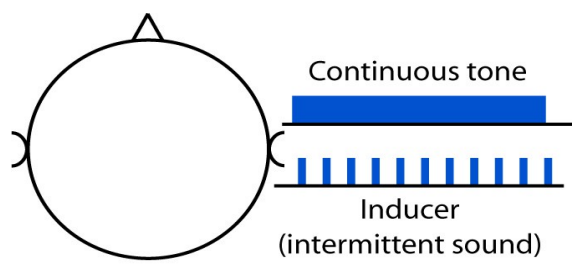

Figures 6. Ipsilaterally loudness adaptation

Ipsilaterally induced loudness adaptation does not depend on the frequency of the continuous tone (Charron and Botte, 1988). It is highly selective in frequency (Charron and Botte, 1988), more than contralaterally induced loudness adaptation. Ipsilaterally induced loudness adaptation is maximal when the continuous tone and inducer have the same frequency. Ipsilaterally induced loudness adaptation depends on the level of the inducer. The increment in level produced to the continuous tone by the addition of the ipsillateral inducer must be $5 \mathrm{~dB}$ or more (Canévet et al., 1983). The greater the increment, the greater is the loudness adaptation (Canévet et al., 1983). Ipsilaterally loudness adaptation is stronger for pure tones than for noises (Scharf and Canévet, 1989). Below $40 \mathrm{~dB}$ SPL, the lower the base level (the continuous tone), the greater is the adaptation (Scharf and Canévet, 1989).

Ipsilaterally and contralaterally induced loudness adaptation differ in a number of ways. Thus, they seems to be independent mechanisms. Charron and Botte (1988) found commun rules in ipsilaterally loudness adaptation and temporary threshold shift (TTS) suggesting a common origin between the two.

\section{RECOVERY FROM LOUDNESS ADAPTATION}

Bertram Scharf studied the recovery from loudness adaptation induced by a contralateral tone (Scharf et al., 1983). When the inducer is turned off (after 3 minutes of listening to the continuous tone plus the contralateral inducer) the recovery from loudness adaptation is small. In the presence of the inducer, the loudness of the continuous tone decreased by $60 \%$ within three minutes. Five minutes after the end of the inducer, loudness was still $50 \%$ below its initial value (at the beginning of the test, before any adaptation). After a long silence (30 s), and without any contralateral inducer, if the continuous tone is turned on, its loudness is still lower than it was initially. This partial recovery has not been found in simple adaptation.

\section{ACKNOWLEDGMENTS}

The author wishes to thank Mary Florentine and Georges Canévet for their precious help in writing this paper. The author also thanks Jacques Chatron for his help in exporting the figures.

\section{REFERENCES}

Botte M.C., Baruch C. and Scharf B. (1986). "Loudness reduction and adaptation induced by a contralateral tone", J. Acoust. Soc. Am. 80 (1), 73-81.

Botte M.C., Canévet G. and Scharf B. (1982). "Loudness adaptation induced by an intermittent tone", J. Acoust. Soc. Am. 72, 727-739.

Canévet G., Germain R., Marchioni A. and Scharf B. (1981). "Adaptation de sonie", Acustica 49 (3), 240-244.

Canévet G., Scharf B. and Botte M.C. (1983). "Loudness adaptation, when induced, is real", British Journal of Audiology 17, 4957.

Canévet G., Scharf B. and Botte M.C. (1985). "Simple and induced loudness adaptation", Audiology 24, 430-436.

Canévet G., Scharf B. and Botte M.C. (1989). "Loudnes adaptation: when and why it occurs", In Proc. 13 ${ }^{\text {th }}$ International Congress on Acoustics, Belgrade, Yugoslavia 1989.

Charron S. and Botte M. C. (1988). "Frequency selectivity in loudness adaptation and auditory fatigue", J. Acoust. Soc. Am. 83, 178-187.

Egan J. P. (1955). "Perstimulatory fatigue as measured by heterophonic loudness balance", J. Acoust. Soc. Am. 27, 111-120.

Fishken D., Arpino E., Testa M. and Scharf B. (1961). "Loudness may adapt, after all", J. Acoust. Soc. Am. 61(1), S61. 
Hellman R., Miskiewick A. and Scharf B (1997). "Loudness adaptation and excitation patterns: effect of frequency and level", J. Acoust. Soc. Am. 101 (4), 2176-2185.

Hood J. D. (1950). "Studies in auditory fatigue and adaptation", Acra Oto-Laryngol., S92.

Miskiewick A., Scharf B., Hellman R. and Meiselman C. (1993). "Loudness adaptation at high frequencies", J. Acoust. Soc. Am. 94 (3), 1281-1286.

Scharf B. (1983). "Loudness adaptation", In Hearing research and theory", J. V. Tobias and E. D. Schbert Eds, Academic Press, $1-56$.

Scharf B. (1995). "Adaptation and attention in psychoacoustics", In Proc. 10 $0^{\text {th }}$ International Symposium on Hearing: Advances in Hearing Research, G. A. Manley, G. M. Klumps, C. Köppl, H. Fastl and H. Oeckinghaus (Eds), World Scientific Publ., Singapore, 365-386.

Scharf B. and Canévet G. (1989). "Loudness adaptation, loudness function, and decruitment: In Fechner day 89, Proceedings of the $5^{\text {th }}$ Meeting of the International Society for Psychophysics, G. Canévet, B. Scharf, A. M. Bonnel and C. A. Possamaï (Eds)., Cassis, France, October 1989, 137-142.

Scharf B., Botte M.C. and Canévet G. (1983). "Récupération après adaptation induite de sonie", L'Année Psychologique 83, 9-24.

Scharf B., Canévet G. and Buus S. (1986). "Additivity of induced loudness adaptation", J. Acoust. Soc. Am. 80, S123. 